\title{
Respiratory Allergy in Children Due to Foods with 7 Tables
}

\author{
Arnaldo Cantani* \\ Pediatric Clinic, University "La Sapienza” Roma, Italy
}

Submission: December 16, 2016; Published: January 09, 2017

*Corresponding author: Arnaldo Cantani, Pediatric Clinic, University "La Sapienza” Roma, Italy

\begin{abstract}
Asthma is one of the most common respiratory manifestations in children and sometimes is provoked by food allergens with two mechanisms: ingestion or inhalation Clinical evidence acquired in recent years shows that the role of foods in asthma is far from being clear, while food allergy (FA) is well known as one of the leading causes of atopic disease. FA-induced manifestations range from urticaria, abdominal pain and anaphylaxis, but above all FA can trigger atopic dermatitis (AD). It may be speculated that, as in AD, food allergens could induce a cutaneous hyperreactivity comparable to the bronchial hyperreactivity (BHR) reported in allergic children with asthma. Eosinophils, as in asthma, seem to have a major role in inducing and maintaining skin lesions. These observations suggest that the characteristic AD chronic skin lesions can be initiated, amplified and perpetuated by immunologic and non immunologic factors acting in various ways and at different levels, thus starting a vicious circle, resulting in different, though synergistic, reactions.
\end{abstract}

Studies have suggested a possible link between inflammatory mediators and food-induced asthma, that can be distinguished from asthma with FA. Nonspecific stimuli can have a role in triggering and worsening skin lesions, however they may play a first part in the induction of BHR. Epidemiologic studies should investigate both facets of the problem, such as asthma with FA and food-induced asthma in children. Personal data on the prevalence of respiratory symptoms in children with FA will be analyzed. We suggest considering in young children food as one of causes of asthma.

Keywords: Food allergy; Asthma; atopic Children; Epidemiology; Cutaneous hyperreactivity; Bronchial hyperreactivity

Abbreviations: FA: Food Allergy; AD: Atopic Dermatitis; BHR: Bronchial Hyperreactivity; DBPCFC: Double-Blind Placebo-Controlled Oral Food Challenge; PTC: prick skin tests; CM: Cow's Milk; RAST: radioallergosorbent test; CMA: CM allergy; HF: hydrolyzed formulas; DBFC: double-blind food challenge;

\section{Introduction}

Although FA is accepted as one of the causes of a number of atopic disorders, such as AD, acute urticaria, vomit-ing, diarrhea, and systemic anaphylaxis, its role in asthma appears to be less clear. In this paper we shall briefly review the current knowledge on food induced asthma, and we shall present some personal data on the prevalence of respiratory symptoms in children with FA.

\section{Definition and Diagnosis}

Correct definition of FA is a prerequisite for effective communication in scientific circles, and for comparison of the results of different studies. Appropriate definition of FA is mandatory to establish both the prevalence of hypersensitivity to a given food and the role of FA in asthma. There is a general agreement that FA is defined as a group of symptoms occurring locally, in the gastrointestinal tract, or in remote organs as a result of an immunologic reaction. Different immunologic reactions may be involved in the clinical manifestations of FA, but the immunologic reaction easiest to demonstrate routinely is the IgE-mediated reaction. Immune complexes, as well as neutrophil chemotactic factor, have been detected in some patients with food induced asthma following the challenge test with the relevant allergen [1,2]. Allergen extracts currently available for skin testing to foods are not standardized, and their stability is usually poorly determined.

For allergen extracts that are rapidly degraded like those of fruits and legumes, skin tests may be falsely negative in food-allergic patients. Conversely, some extracts may contain irritating substances, causing false positive skin tests. The titration of food-specific IgE is available only for certain foods, and in contrast with better characterized inhalant allergens, the sensitivity of the test is not yet known for most unpurified food allergens. Moreover, as in inhalant allergen sensitivity, the presence of food IgE in serum does not always correlate with symptoms [3]. Symptomatic hypersensitivity is present when 


\section{Global Journal of Otolaryngology}

symptoms occur during food ingestion and a specific immune response can be shown. Asymptomatic hypersensitivity exists when no symptom occur during food ingestion but a specific immune response can he shown (Table 1). Double-blind placebo-controlled oral food challenge (DBPCFC) is considered the "golden standard" for the diagnosis of FA in patients enrolled in research studies or in clinical trials [4].

Table 1: Food hypersensitivity.

\begin{tabular}{|c|c|}
\hline Symptomatic & Asymptomatic \\
\hline $\begin{array}{c}\text { Symptoms during food ingestion } \\
\text { specific immune response } \\
\text { positive challenge with the } \\
\text { relevant food }\end{array}$ & $\begin{array}{c}\text { No symptoms during food } \\
\text { ingestion specific immune } \\
\text { response negative challenge with } \\
\text { the relevant food }\end{array}$ \\
\hline
\end{tabular}

\section{Epidemiology}

The epidemiology of asthma triggered by FA has not been fully investigated. Several authors have examined FA in general as opposed to food-induced asthma specifically. Even in studies in which food ingestion and asthma have been associated with every suboptimal methodology has been used to confirm the relationship. The number of subjects with proven foodinduced asthma by DBPCFC has been rather small. Anyway, the prevalence and incidence of children with food-induced asthma has not been entirely studied. FA may trigger allergic respiratory symptoms through two main routes: ingestion or inhalation. Exceptionally, life-threatening systemic reactions, including asthma, have been shown in children with FA after inhalation of the offending food. Recently, an Italian teenager girl, allergic to cow's milk (CM), suddenly died for a severe asthma attack following CM inhalation when she entered into a diary product factory, with no indication of CM selling [5].

Table 2: Clinical presentation of children or adolescents with foodinduced asthma.

\begin{tabular}{|c|}
\hline High level of total serum IgE \\
\hline Associated Symptoms \\
\hline Atopic dermatitis \\
\hline Urticaria \\
\hline Angioedema \\
\hline Lip edema \\
\hline Vomit?ing \\
\hline Diarrhea \\
\hline Anaphylaxis \\
\hline
\end{tabular}

Respiratory symptoms as the only manifestation of FA or even in concert with cutaneous and gastrointestinal symptoms are not common [6]. According to several studies, children with asthma, who are allergic to foods, present some particular features. More frequently they are children or adolescents, furthermore, they have AD and a significantly high mean level of total serum IgE (Table 2). The reason for this high IgE level is not completely known, but could be related to the presence of $\mathrm{AD}$ in these patients. High IgE levels, in fact, were reported in subjects with asthma with AD. Alternatively, FA may occur in patients who are "high IgE responders" and more prone to become sensitive towards many allergens, including foods. Therefore children with asthma with a history of $\mathrm{AD}$ and/or elevated total serum IgE level should be carefully assessed for a possible FA (Table 3) [7].

Table 3: Data to Be Collected in Children with Suspected FoodInduced Asthma.

\begin{tabular}{|c|}
\hline History \\
\hline Most recent symptoms \\
\hline Number of symptoms \\
\hline Description of symptoms \\
\hline Timing of onset of symptoms \\
\hline Quantity of food eliciting symptoms \\
\hline Associated symptoms \\
\hline
\end{tabular}

In reviewing the presentation of food-associated symptoms in 367 children with asthma, evaluated at the National Jewish Center, Bock et al. [6] showed that 257 children (70\%) had a history of specific foods being as-sociated with the onset of asthma symptoms. Of these 257, 163 (63\%) had some symptoms produced during positive DBPCFC. Fifty-seven out of 257 children (22\%) with positive DBPCFC exhibited wheezing as one of the symptoms. Five out of 257 patients (2\%) had wheezing as the only symptom. In addition, 203 children underwent DBPCFC because of a history of food-associated symptoms since wheezing was not suspected of being precipitated by food ingestion. Six out of 203 children (3\%) had wheezing as one of the elicited symptoms, but in 5 out of 6 the wheezing was quite mild. None of the children had wheezing as the only symptom of a food allergic reaction [5].

To determine the prevalence of FA as a cause of exacerbation of asthma, Onorato et al. [7] studied 300 patients with asthma (7 months-80 years). They confirm that asthma induced by FA has a low prevalence (2\%), even in a population attending a speciality clinic. A similar prevalence is reported by Novembre et al. [8], who studied 140 children with asthma. The presence of specific IgE was investigated with prick skin tests (PTC) and, in some cases, with RAST (radioallergosorbent test). The patients were divided into 2 subgroups on the basis of clinical history: in 92 patients asthma was the only symptom, in 48 patients asthma was associated to other symp toms of FA. Using open food challenge tests, these authors observed symptoms related to FA in 16 out of $140(11.4 \%)$ children. Respiratory symptoms were observed in 13 out of 140 children (9.2\%), and one of these 13 had asthma as the only symptom. Moreover, 12 out of 13 children with asthma had associated symptoms (cutaneous, gastrointestinal), and 8 of out 140 (5.7\%) children had immediate or delayed onset asthma [7].

The association between FA and chronic asthma has been studied by Zimmerman et al. [9]. These authors showed that food allergic children with asthma had more often AD, high IgE serum levels, multiple positive RAST, and chronic wheezing in 
comparison to non food-allergic children. In addition, it was shown that highly atopic children (multiple positive RAST and high IgE serum level) had a significantly higher prevalence of chronic asthma. The authors conclude that highly atopic children are more prone to develop bronchial inflammation which induces chronic persisting symptoms.

In a previous study [10] we studied seventy-nine children, (aged 6 months- 10 years, median age 24 months), fulfilling the criteria of Hanifin \& Rajka [11] for the diagnosis of AD, underwent the challenge test. In all children PTCs and RAST for CM protein and egg were performed. Following 4-6 weeks of a CM and eggfree diet, 113 open challenge tests were perform $\urcorner$ ed in the hospital. Nine out of 70 children had asthma at the challenge test with CM (13\%). Three children out of 9 (33\%) presented asthma within 2 hours following food challenge. In particular, 2 out 3 children presented asthma associated with pruritus, urticaria and erythema and 1 out of 3 children presented isolated asthma. None of 38 children presented asthma folılowing the challenge test with egg.

Table 4: Clinical features of 42 children with IgE-CMA according to the appearance of asthma following DBPCFC with CM.

\begin{tabular}{|c|c|c|c|c|c|}
\hline \multicolumn{6}{|c|}{ Asthma } \\
\hline & YES & $\%$ & NO & $\%$ & TOTAL \\
\hline No of children & 11 & & 31 & - & 42 \\
\hline \multicolumn{6}{|c|}{ Sex } \\
\hline Male & 8 & 73 & 22 & 71 & 30 \\
\hline Female & 9 & 27 & 9 & 29 & 12 \\
\hline $\begin{array}{l}\text { MEDIAN AGE } \\
\text { (mos) }\end{array}$ & $\begin{array}{c}36(10- \\
72)\end{array}$ & & $\begin{array}{c}30(10- \\
54)\end{array}$ & & \\
\hline \multicolumn{6}{|c|}{ Clinical Presentation } \\
\hline $\begin{array}{c}\text { Atopic } \\
\text { Dermatitis }\end{array}$ & 2 & 18 & 25 & 80 & 27 \\
\hline $\begin{array}{c}\text { Atopic } \\
\text { Dermatitis + } \\
\text { asthma* }\end{array}$ & 7 & 64 & 3 & 10 & 10 \\
\hline Anaphylaxis & 2 & 18 & 3 & 10 & 5 \\
\hline \multicolumn{6}{|c|}{ Rast Class } \\
\hline 3 & $4 / 11$ & $(36)$ & 14 & 45 & 18 \\
\hline$<3$ & $7 / 11$ & 64 & 17 & 55 & 24 \\
\hline
\end{tabular}

${ }^{*} \mathrm{p}=0.0001$

Moreover, 42 children (median age 20 months) attending our clinic, with proven IgE-mediated CM allergy (CMA) were' included in a prospective study to investigate the prevalence of CM-induced asthma (Table 4). All children presented positive skin-tests and RAST to CM proteins and immediate reactions following DBPCFC with CM. Eleven children out of 40 (27\%) developed asthma 10 to 120 minutes after the challenge: of the 11 children, 6 experienced asthma as the only symptom, and 5 presented vomiting, erythema, urticaria, angioedema and lip edema associated with asthma, respectively. In 3 out of 11 children asthma occurred for the first time after the challenge. In addition, 5 children out of 11 experienced asthma even following the challenge with some hydrolyzed formulas (HF); in particular, in 4/5 children asthma occurred with a partly whey $\mathrm{HF}$ and one with an extensively casein HF. Interestingly, 3 out of 5 children had asthma only with a HF, thus suggesting that hidden allergenic epitopes may be exposed during hydrolysis procedure.

In a study on 94 children with asthma using clinical history, PTC, radioallergosorbent test (RAST) and double-blind food challenge (DBFC) we have shown that food is one of the causes of asthma. Out of 94 asthmatic children we found that 23 also had AD (24.6\%); 14/23 children ( 8 boys and 6 girls aged 2-6 years) had positive PTC, RAST and DBFC. In all 14 patients the main symptom after DBFC was asthma, however associated in 5 cases with erythema, urticaria, vomiting, lip edema and angioedema. In 9 children asthma was provoked by $\mathrm{CM}$, in 2 by partly $\mathrm{HF}$, in 2 by extensively HF and one by fish, Moreover in 3 children asthma appears with very little doses of $\mathrm{CM}$ : one drop in one case and $2 \mathrm{ml}$ in two cases [12]. Completely different, but similar in the conclusion, are the respiratory reactions induced by food challenges in children with AD or pulmonary disease (Table 5) [13-15].

Table 5: Respiratory reactions induced by food challenges in children with pulmonary disease or AD.

\begin{tabular}{|c|c|c|c|}
\hline Foods (\%) & 13 & 14 & 15 \\
\hline Type of disease & \multicolumn{2}{|c|}{ Respiratory } & AD \\
\hline Egg & 46 & $19^{*}$ & 51 \\
\hline CM & 19 & 27 & 28 \\
\hline Peanuts & 6 & $28^{*}$ & 6 \\
\hline Wheat & 5 & $3^{*}$ & 5 \\
\hline Soy & 8 & 3 & 5 \\
\hline Fish & $15^{*}$ & & 3 \\
\hline Nuts & & & \\
\hline
\end{tabular}

* indicates monosymptomatic children

\section{Discussion}

The relationship between FA and asthma is based on several considerations. First, inhaled food allergens may reach the respiratory tract directly. On the contrary, food allergens, raw or cooked, may reach the target organ after a number of steps such as ingestion, digestion, uptake through the intestinal mucosa, absorption into the blood stream, etc. All these steps 


\section{Global Journal of Otolaryngology}

may significantly interfere with the immunogenicity and allergenicity of foods, as a consequence allergenic determinants may be destroyed or hidden allergenic epitopes may be exposed. As a result, the immunogenic and allergenic potency of foods may be reduced or even increased. Moreover, patients with FA may have coexisting inhalant allergy and other specific factors, besides allergens, (such as pollutants, smoking, or emotions, can increase bronchial reactivity (Table 6). Foods may also induce respiratory symptoms involving non reaginic mechanisms. For instance, substances as egg, milk, nuts, chocolate and food additives (sulphites, benzoate, tartrazine) may cause wheezing in patients with asthma but do not elicit a reaction when ingested (oral challenge test).

Table 6: Food Allergy and Asthma.

\begin{tabular}{|c|}
\hline Does food allergy precipitate asthma? \\
\hline Does food allergy induce chronic asthma? \\
\hline What is the prevalence of food induced asthma? \\
\hline Do cross reactions between inhalant and food allergens precipitate \\
asthma?
\end{tabular}

It has been demonstrated that these substances may enhance airway reactivity instead of provoking airways obstruction directly [16]. Once airway reactivity is enhanced, other common triggers of asthma, such as cold air or drinks, exercise [17] or other environmental factors, could readily precipitate acute bronchoconstriction. It has been reported that no specific airway reactivity increased after DBPCFC with cold drinks but not after challenge with soda or water [18].

\section{Conclusion}

There is not doubt that foods may induce FA in children. However, at present, there are no definite data on the prevalence of such association. According to our studies, children with asthma and $\mathrm{AD}$, have a significantly higher prevalence of food induced asthma. Mechanisms, cells and mediators involved in food induced asthma are not completely known. Moreover, whether airway reactivity increases following a positive challenge test with the offending food, or, daily, if the child has not a good compliance to the diet, is a crucial point which should be investigated in future (Table 7), Similar phenomenon has been demonstrated to occur in patients with asthma when they are daily exposed to the relevant inhalant allergens.

Table 7: Patterns of Management of Food-Induced Asthma.

Children with anaphylaxis accompanied by wheezing

Children with chronic asthma on a restricted diet because parents and/or physicians claim that food(s) precipitate wheezing

Children who improved on a restricted diet without challenging the association between foods and symptoms

Children on a restricted diet because positive skin test and/or RAST responses to food(s)

\section{References}

1. Paganelli R, Levisky RJ, Brostoff J, Wraith DG (1979) Immune complex containing food proteins in normal and atopic subjects after oral challenge and effect of sodium cromoglycate on antigen absorption. Lancet 1(8129): 1270-1272.

2. Papageorgiou N, Lee TH, Nagakura T, Cromwell 0, Wraith DG, Kay AS (1983) Neutrophil chemotactic activity in milk-induced asthma. J Allergy Clin Immunol 72(1): 75-82.

3. Giampietro PG, Ragno V, Daniele S, Cantani A, Ferrara M, et al. (1992) Soy hypersensitivity in children with food allergy. Ann Allergy 69(2): 143-146.

4. Cantani A (1999) Pediatric asthma before treated should be prevented. Eur Rev Med Pharmacol Sci 3(5): 237-238.

5. Vargiu A, Vargiu G, Locci F, Del Giacco S, Del Giacco GS (1994) Hypersensitivity reactions from inhalation of milk proteins. Allergy 49(5): 386-387.

6. Bock SA (1993) Food hypersensitivity and asthma in children. In: Tinkelman DG, Naspitz CK. Childhood asthma. Pathophysiology and treatment. Marcel Dekker Inc, New York, USA, pp 537-551.

7. Onorato J, Merland N, Terral C, Michel FB, Bousquet J (1986) Placebocontrolled double-blind food challenge in asthma. J Allergy Clin Immunol 78(6): 1139-1146.

8. Novembre E, De Martino M, Vierucci A (1988) Foods and respiratory allergy. J Allergy Clin Immunol 81(5 Pt 2): 1059-1065.

9. Zimmerman B, Chambers C, Forsyth S (1988) Allergy in asthma II. The highly atopic infant and chronic asthma. J Allergy Clin Immunol 81: 7177.

10. Meglio P, Giampietro PG, Farinella F, Cantani A, Businco L (1989) Personal experience in the diagnostic procedures in children with atopic dermatitis and food allergy. Allergy 44(9): 165-173.

11. Hanifin JM, Rajka G (1980) Diagnostic features of atopic dermatitis. Acta Dermatol Venereol 92: 44-47.

12. Cantani A, Gagliesi D (1998) Food allergens provoke asthma in children. ERS Annual Congress, Geneva, Eur Respir J 12(28): 443s.

13. James JM, Eggleston PA, Sampson HA (1994) Airway reactivity changes in food-allergic, asthmatic children undergoing double-blind, placebocontrolled food challenges. Am J Respir Crit Care Med 149(2): 59-64.

14. Bock SA (1992) Respiratory reactions induced by food challenges in children with pulmonary disease. Pediatr Allergy Immunol 3(4): 188198.

15. Sampson HA, James JM (1992) Respiratory reactions induced by food challenges in children with atopic dermatitis. Pediatr Allergy Immunol 3(4): 195-200.

16. Bahna S (1991) Food allergy and the respiratory tract. Allergie immunol 23: 384-386.

17. Kidd JM, Cohen SH, Sosman AJ (1980) Food-dependent exerciseinduced anaphylaxis. J Allergy Clin Immunol 71(4): 407-411.

18. Wilson N, Vickers H, Taylor G, Silverman M (1982) Objective test for food sensitivity in asthmatic children: increased bronchial reactivity after cola drinks. Br Med J 284(6324): 1226-1268. 
Your next submission with JuniperPublishers will reach you the below assets

- Quality Editorial service

- Swift Peer Review

- Reprints availability

- E-prints Service

- Manuscript Podcast for convenient understanding

- Global attainment for your research

- Manuscript accessibility in different formats

( Pdf, E-pub, Full Text, Audio)

- Unceasing customer service

Track the below URL for one-step submission https://juniperpublishers.com/online-submission.php 